\title{
Sichere Drahtfixation bei der Seldinger-Technik
}

Diese Situation ist jedem Urologen bekannt: Beim Wechsel vom Führungsdraht auf einen Ureterkatheter, einen Nierenfistelkatheter oder ein Instrument in der Seldinger-Technik disloziert der oftmals mühsam eingebrachte Draht. Ein einfacher Trick hat sich hier bewährt.

Ein zu großer Schiebewiderstand oder aber ein Absprachefehler mit dem Operationsassistenten können bspw. die Ursache eines dislozierten Führungsdrahts sein. Manchmal reicht eine Unachtsamkeit aus, eine Bewegung des Patienten oder eine Falte in den Abdecktüchern, um aus einem scheinbar problemlosen Wechsel eine aufwendige Neuanlage mit Korrekturen werden zu lassen. Hier hilft die Fixation des Drahts, des Doppel-J- (DJ) oder des Ureterkatheters (UK) mit dem Fingernagel der Haltehand: Wird der Daumennagel im rechten Winkel zum Zeigefinger aufgestellt, kann das Objekt nicht mehr verrutschen. Auf diese Weise ist eine sichere, kraftarme und bequeme Fixation auch über längere Zeiträume gewährleistet.

Dr. Andreas Wiedemann, Witten

Korrespondenz:

Dr. Andreas Wiedemann

Evangelisches Krankenhaus

im Diakoniewerk Ruhr gGmbH,

Lehrstuhl für Geriatrie

der Universität Witten/Herdecke

Pferdebachstr. 27

58455 Witten

Tel. 02302/175-2521

Fax. 02302/175-2075

awiedemann@diakonie-ruhr.de

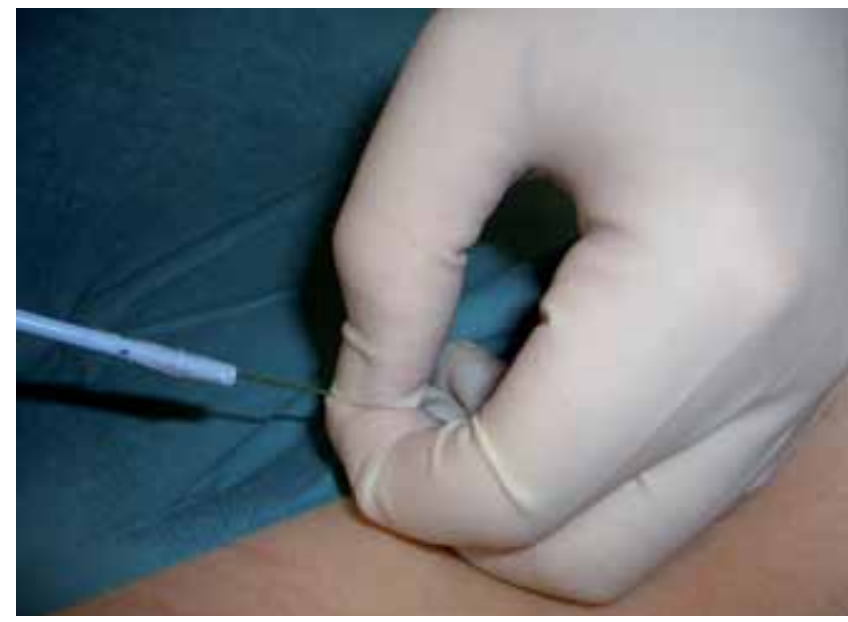

Abb. 1 Sichere Drahtfixation bei der Seldinger-Technik mit dem Daumennagel im rechten Winkel zum Zeigefinger. 